A detailed chart correlates the events recorded for the various zones in Ireland with the stratigraphy worked out particularly by Godwin for England, Faegri for Norway, and Jessen for Denmark. This would have been more complete if the British data could have included reference to Pennington's work on the stratigraphy of the floor of Lake Windermere and Mitchell's pollen-analytical work with the South Berwickshire clays, which collectively provide some of the best evidence for Late-glacial chronology in Great Britain. This omission is, however, explained by the delay of two years during which this extremely important work was passing through the press.

H. G. BAKER

\section{GRAVITY AS A GEOLOGICAL FACTOR}

A

GEOPHYSICAL Discussion on "Gravity as a Geological Factor" was held at the Royal Astronomical Society on March 3. The proceedings opened with a paper by Prof. O. T. Jones, who mentioned the various effects due to gravity, namely, landslips, creep and submarine slumping, all showing downhill movement of material. Among these effects are the structures proved in the Jurassic ironfield of Northamptonshire and the flap and cascade structures described from Iran. More doubtful in its application is the sliding under gravity in the Alps. Prof. H. Jeffreys suggested that the main effect of compression was to elevate the sedimentary rocks to such a height that the nappes became unstable and flowed downhill under gravity, thus producing the Alpine Nappes.

Prof. H. Jeffreys, in his contribution, said that after its early successes the idea of isostasy led to the supposition that at depths exceeding $50-100 \mathrm{~km}$. the material behaves like a viscous fluid for low stresses lasting a long time. The added weight produced by sedimentation is able to depress the crust, but as shown by Morley Davies and by E. M. Anderson, there is a limit to this effect, and something more is needed to produce the sinking than viscous outflow.

There are two types of distribution of viscosity at depth : in the first, the $20 \mathrm{~km}$. immediately under the surface has a finite strength of the order of laboratory strengths, and below this the material is viscous to great depths. In the second type of distribution the viscosity is confined to an intermediate layer. Both are contradicted by the observed distribution of gravity anomalies.

The sinking of the crust in regions of heavy sedimentation can no longer be regarded, Prof. Jeffreys said, as due to outflow produced by load. It needs spontaneous changes in a strong substratum, probably the same as those producing deep-focus earthquakes. Long fractures in a strong substratum and the infall of the outer parts could explain sinking geosynclines, ocean deeps, and rift valleys.

Dr. A. J. Bull described two types of structure which he considers have been produced by the move. ment of strata downhill under the force of gravity; namely, the Jura Mountains, which have moved bodily on the anhydrite beds, and a simple overfold, examples of which were shown from the London clay of Brockley and the Mesozoic cover of the Aar granite, Switzerland. He considers that gravity tends to equilibrium in the earth's crust, but this can be disturbed by radioactive heat and by changes in the specific gravity which the heat can induce.
Dr. J. G. Oldroyd referred to the rock markings mentioned by Prof. Jeffreys, and suggested that they might indicate the presence of regions in a moving rock where the yield-point is not exceeded. Slight inhomogeneity in the rock and boundary irregularities could cause the regions of actual plastic flow to occur in a complicated pattern, which might well be preserved as rock markings. Sudden fracture of a flowing rock can be accounted for by the hypothesis that a solid can rupture by flow or by fracture, with different stress criteria for the two types of failure. A gradual reduction of the hydrostatic pressure on a rock, while not interfering with the continuance of plastic flow, could make a brittle fracture increasingly probable.

Mr. N. L. Falcon showed illustrations of folding produced by gravity in the south-west of Persia. These structures were first described by Dr. J. V. Harrison and himself in the Geological Magazine of 1934. Particular interest is attached to the large size of the structures produced, although they are subsidiary to the main folding of the region. Their mode of origin appears to have been generally accepted by geologists throughout the world. Dr. Falcon referred to the negative gravity anomalies in the East African Rift Valley, which may be due to a considerable thickness of light sediments. Further examination is necessary in the way of bore holes and geophysical work before definite conclusions can be drawn.

Prof. S. E. Hollingworth discussed the strong disturbances produced by gravity in the Mesozoic of the Midlands, resulting in cambering and valley bulging. This has entailed a flowage in the rocks towards the valleys to a depth of at least $100 \mathrm{ft}$. below the surface. Tension in the interfluves and valley sides has produced step-and trough-faulting, while the clays at the foot of the valley slopes were crumpled, locally overturned and broken by reversed faults. He regards these structures as periglacial phenomena associated with deep perma-frost, in which the segregation of ground-water during freeze and thaw processes has played a vital part. The increased dip at the lower end of a downfaulted block is the result of sagging during tension.

Nature has in the Midlands made some moderatescale experiments, which may help to explain the larger tensional block-faulted structures in the Western United States and in regions of rifting, when the movement of the substratum is a matter of speculative inference.

Dr. R. I. B. Cooper commented on Prof. Jeffreys's suggestion that the major variations in the level of the earth's surface might be attributed to spontaneous changes in the substratum. He said that if they were due to density variations above a given level, then they would be equivalent to the Hayford conception of isostasy ; on the other hand, if the material circulated, then the principle would resemble that of Meinesz's convection currents. His own opinion is that the approximate constancy of mass per unit area over the earth's surface is a remarkable experimental fact; for example, the mass deficiency of the oceans would be expected to give a gravity deficiency of 300 mgal., whereas, in fact, variations of only about \pm 20 mgal. are generally found.

Dr. Gilbert Wilson briefly summarized some cases in which sliding due to gravity has been invoked by French and Swiss geologists. Schardt was recognized as having first suggested that the nappes, after initial uplift, slid downwards under their own weight. The classic nappe theory, however, displaced this hypo- 
thesis until Schneegans (Mém. Serv. Carte géol. France, 1938) suggested that the "Nappe du Flysch de l'Ubaye-Embrunais" in the French Alps has flowed forward like tar under the influence of gravity. He was shortly followed by Lugeon and Gagnebin, who, in a series of publications (particularly in 1941), demonstrated the importance of movement due to gravity both in the formation of the pre-Alps and among the Helvetic nappes. Despite these appeals to gravity, Lugeon and Gagnebin consider that gravitational sliding is not to be considered a substitute for the classical theories of mountain building -it is complementary to them.

Dr. Wilson went on to consider Gignoux's review (1948) of the subject (Bull. Soc. géol. France, 5, 18, 739). The latter appealed to the similarities between alpine structures and those seen in glaciers where gravity takes a predominant role. Gignoux also advocated the use of true-to-scale models as a means of appreciating the relation between structure and rock-movement. Such models should have true dynamic similarity, and it was felt that, by the use of such materials as soft wet clay for 'rocks', one would be able to "understand the real orogenic phenomena .... and perceive the nappes flowing by gravity" (Gignoux, 1948, loc. cit., 758).

Dr. F. M. Trotter spoke of the use of gravity determinations in the elucidation of concealed structures in north-western England. The results of the gravimeter work by the Anglo-Americal Oil Company have been published in the Quarterly Journal of the Geological Society. A detailed survey with numerous stations at short intervals has been recently completed over an area of some forty square miles of that part of the South Lancashire Coalfield which lies beneath New Red Rocks. Relative close-packing of isogams, interpreted as indicative of lines of faulting, shows in general a broad correspondence with known lines of major fracture. There are, however, exceptions, and at present it would be unwise to claim for this mothod too great a precision ; but the method is certainly useful in helping to determine sites at which deep borings for coal to depths of the order of 2,000-4,000 ft. would not be crossed by major faults.

\section{SUMMARY TABLES OF BIOLOGICAL TESTS}

T HE Chemical-Biological Coordination Center of the National Research Council of the United States has recently announced that the publication entitled "Summary Tables of Biological Tests"* is available free of charge. The Center was established in July 1946 to succeed the war-time Insect Control Committee, and like this latter body it functions by means of subcommittees dealing with various phases of its programme. Some idea of the scope of its activities is conveyed by enumeration of these subcommittees, which deal respectively with physical chemistry, biochemistry, organic chemistry, chemotherapy, entomology, malignancy, mammalogy, medicine, microbiology, veterinary medicine, physiology-pharmacology, plant sciences and sanitary engineering; there are also a chemical codification

* Summary Tables of Biological Tests. Sponsored by the ChemicalBiological Coordination Center. Vol. 1, No. 1, October. Pp. vi +58. Vol. 1, No. 2, December. Pp. vit,
National Research Council, 1949.) panel, a biological codification panel and an inorganic chemistry panel.

The objects of the Center are stated to be : (a) to assemble and organise data for the purpose of correlating chemical structure with biological activity, (b) to sponsor the preliminary screening of chemicals to determine their biological effects, and (c) to sponsor the preparation of reviews dealing with the correlation of chemical structure with biological activity. Financial support is provided by the American Cancer Society, the Department of the Army (Chemical Corps, Corps of Engineers, Quartermaster Corps, Surgeon-General's Office), the Department of the Navy (Office of Naval ResearchDivision of Medical Sciences) and the United States Public Health Service (National Cancer Institute). A system is in operation for soliciting materials and arranging for their testing.

The first two numbers of Vol. 1 of "Summary Tables of Biological Tests" contain fifty-eight and sixty-two pages respectively. Tables are arranged according to the type of test employed (for example, antibacterial, arachnidicide, fungicide, insecticide, plant growth regulator, insect and rat repellency, rodenticide, mammalian toxicity, antimalarial, brucellosis and cancer tests in No. 1, and the same plus snail control and rickettsia in No. 2), the test technique is described and the chemicals tested are listed alphabetically (Chemical Abstracts system) and their structural formulæ are reproduced.

From the first two numbers, it is clearly impossible to judge all the activities of the Coordination Center; but it can safely be said that every type of worker is likely to find within the pages of these "Summary Tables" collected information which will be of value to him in his studies, and for the publication of which he will have cause to be grateful to the National Research Council.

\section{KOSSUTH AWARDS IN HUNGARY FOR 1950}

K OSSUTH Awards in Hungary were first made in 1948 for outstanding work of a life-time, and in 1949 they were given for such achievements since the end of the Second World War. It has now been decided to make the Awards in recognition of outstanding work during the past year, and this practice will be continued in the future. Winners of the Awards for 1950 have recently been announced as follows, the value of the prizes being 10,000 forints except where otherwise stated.

Physics : the first prize (20,000 forints) jointly to Prof. P. Gombás for his work on the theory relating to the structure of noble metals and for his two books on atom physics, and to Prof. T. Neugebeuer for his achievements in electron-physics research.

Agricultural Science : Prof. R. Manninger $(20,000$ forints) for the discovery of a vaccine against swine erysipelas; K. Sedlmayer, plant improver, for the improvement of sugar beet, autumn barley, flax and vetches; and $L$. Kreybig, research director, for work on the drafting of a geological map of Hungary and his new method of applying artificial fertilizers.

Mathematics : Prof. L. Rédei (20,000 forints) for research in the theory of numbers and the theory of groups; Prof. L. Kalmár, for investigations in mathematical logic; and Prof. B. Szökefalvi-Nagy, for work on Hilbert space and Fourier series. 